Article

\title{
Bioremoval of Phenol from Aqueous Solutions Using Native Caribbean Seaweed
}

\author{
Abel E. Navarro ${ }^{1, *}$, Anibal Hernandez-Vega ${ }^{2}$, Md Emran Masud ${ }^{1}$, Loretta M. Roberson ${ }^{3}$ \\ and Liz M. Diaz-Vázquez ${ }^{2}$ \\ 1 Science Department, Borough of Manhattan Community College, The City University of New York, \\ New York, NY 10007, USA; mem902@nyu.edu \\ 2 Department of Chemistry, University of Puerto Rico at Rio Piedras, San Juan, PR 00931, USA; \\ anibal.hernandez@upr.edu (A.H.-V.); liz.diaz2@upr.edu (L.M.D.-V.) \\ 3 Department of Environmental Sciences, University of Puerto Rico at Rio Piedras, San Juan, PR 00931, USA; \\ loretta.roberson@gmail.com \\ * Correspondence: anavarro@bmcc.cuny.edu; Tel.: +1-212-220-8000; Fax: +1-212-748-7471
}

Academic Editor: Yu-Pin Lin

Received: 8 July 2016; Accepted: 7 December 2016; Published: 22 December 2016

\begin{abstract}
Among several Puerto Rican algae, Sargassum sp. (SG) and Chaetomorpha (CM) showed the highest phenol adsorption capacity from aqueous solutions and were used in optimized adsorption batch experiments at room temperature. The effects of $\mathrm{pH}$, adsorbent dose, phenol concentration, salinity and presence of interfering substances were evaluated. Initial solution $\mathrm{pH}$ exhibited a strong effect, mainly on the phenol aqueous chemistry; showing the maximum adsorption at $\mathrm{pH} 10$. Sorption isotherm results were modelled according to the Langmuir, Tempkin and Freundlich equations. Isotherm modelling indicated a maximum adsorption capacity $\left(\mathrm{q}_{\max }\right)$ of 82.10 and $17.7 \mathrm{mg}$ of phenol per gram of SG and CM, respectively. Salinity and presence of detergent in the matrix solution showed a positive effect on the adsorption, suggesting that adsorption of phenol was mostly driven by polar forces and not by ionic exchange. On the other hand, presence of heavy metals like copper, lead and cobalt had a negative effect on the adsorption. According to these results, the potential formation of hydrogen bonds between the algae and phenol is proposed as the main adsorption mechanism. These results provide further insight into the adsorption mechanism of phenol and their use as inexpensive adsorbents for the treatment of phenol-containing wastewaters.
\end{abstract}

Keywords: adsorption; marine algae; phenol; $\mathrm{pH}$; isotherm

\section{Introduction}

Phenol and its derivatives are mainly generated by petroleum industries. Due to their toxicity, these compounds are considered as priority pollutants by the Environmental Protection Agency (EPA) and the World Health Organization (WHO), who have established the maximum level of phenol concentration allowable in drinking water at $1 \mu \mathrm{g} \cdot \mathrm{L}^{-1}[1,2]$. When phenols are released into the water, some of them remain in solution or react, producing even more toxic substances and therefore threatening the aquatic life by entering the food chain. The treatment processes for phenolic wastewater have been classified into two principal categories [3]: (i) recuperative process such as adsorption into porous solids, osmosis and solvent extraction and; (ii) destructive process by their oxidation with hydrogen peroxide, manganese oxides and ozone. Recent studies utilized enzymatic degradation [4] and naturally occurring adsorbents [5-8] to control the contamination of liquid effluents by phenol and derivatives.

Among these techniques, adsorption has reported high phenol removal, low operative costs and innocuous side effects caused to the environment. The high surface area per unit mass of activated 
carbon converts it into one of the most efficient adsorbents in the removal of organic pollutants from aqueous solutions [9-11]. Nevertheless, due to the relatively high cost of activated carbons there have been attempts to utilize low cost adsorbents to remove trace organic and inorganic contaminants from wastewaters.

In developing countries, industries cannot afford to use conventional wastewater treatments such as activated sludge, because they are not cost-effective, require constant monitoring, energy consumption and special technical training. On the other hand, marine seaweeds line up the shores of Caribbean islands (such as Puerto Rico) causing more detriment than asset to the surrounding community. Bioremediation as an area of biotechnology has explored the potential use of these seaweeds as adsorbents of pollutants. Different types of algae have been studied for the removal of heavy metals [12-14], phenolic compounds [15,16] and dyes [17,18] yielding positive results. Other alternative materials have also been studied, for example natural clays reported a high affinity towards inorganic and organic pollutants [19-22] and are extracted from natural mines at minimal cost.

Previous studies [14] have determined that cross-linkage of brown seaweeds with calcium chloride enhances their mechanical properties and affinity towards heavy metals. Rubin et al. [16] have previously observed that raw algae were easily decomposed by phenolic solutions and that decomposition products interfere in the determination of phenols in aqueous solutions. It was discovered that a cross-linkage with calcium chloride resolved this issue. This improvement was attributed to the stabilization of alginate molecules by the formation of the characteristic alginate arrangement known as the egg-box structure [14,23].

Several phenol adsorption studies have been conducted using different types of marine algae, but few of them have established a mechanism corresponding to the results or optimized equilibrium parameters [21]. Furthermore, a detailed discussion on the relationship of the chemical characterization of the algal biomass and its adsorption performance has not been clearly established in the literature. This study reports a comparison into the adsorption behavior of phenol across native marine algae from a structural, mechanistic and equilibrium point of view.

\section{Materials and Methods}

\subsection{Algal Biomass}

The marine algae Chaetomorpha (CM), Sargassum sp. (SG), Chlorella vulgaris (CV), Osmundaria (OD) and Ulva lactuca (UL) were collected from Puerto Rican beaches during the Spring 2015. Algal samples were vigorously and sequentially rinsed with tap, distilled and deionized water, to assure the elimination of soluble substances and adhered particles. Then, algae were sun-dried and crushed with a mortar and pestle. Finally, the algae were sieved to a homogenous size (particle size between 100 and $180 \mu \mathrm{m}$ ) and stored in glass containers on the bench at room temperature until their use. Algal samples were classified as green algae (CM, CV and UL) and brown algae (OD and SG).

\subsection{Reagents and Solutions}

Stock solutions of 1000 ppm (mg of phenol per liter of solution) were prepared by dissolving Phenol (Analytical grade, Fisher Scientific) in deionized water. Solutions were stored in amber glass bottles under refrigeration. Solution of varying concentrations were produced by dilution of stock solutions until the desired concentration was reached. No buffer was used in the preparation of the solution to minimize salt effects in the experiments. This protocol has been previously used with other inorganic and organic pollutants [12-18]. The initial $\mathrm{pH}$ of each solutions was adjusted to the required values by adding aliquots of diluted $\mathrm{HCl}$ and $\mathrm{NaOH}$ prior to contact with the adsorbents.

Finally, stability of phenol in solution was monitored by UV spectrophotometry under the same working conditions, showing a stability of more than $24 \mathrm{~h}$. 


\subsection{Characterization of Adsorbents}

Preliminary adsorption experiments indicated that SG and CM had the most efficient adsorption amongst the five algae samples. Therefore, the biomass characterization focused on these two samples to evaluate the chemical, textural, and thermal properties of both adsorbents. The presence of organic functional groups of SG and CM were analysed by Fourier transform infrared spectroscopy, and recorded on a Frontier FTIR spectrometer (Perkin Elmer, Waltham, MA, USA), which provides counts using an Attenuated Total Reflectance (ATR) accessory for measurement in solid state. FTIR allowed us to identify the functional groups that could be potentially involved in phenol adsorption.

Morphology and textural analysis of both adsorbents was performed under a scanning electron microscope, by using a Tabletop microscope, model TM3000 (Hitachi, New York, NY, USA). Both samples were directly measured in the instrument without gold coating. Simultaneously, elemental analysis of SG and CM was conducted by energy dispersive X-ray spectrophotometry (EDS) (Bruker, Billerica, MA, USA) with a spectrometer, model Quantax 70. This technique allowed us to determine the percent abundance of key elements that were present on the algae surface.

Finally, the thermal resistance and mechanical properties of both adsorbents were determined by thermogravimetric analysis (TGA) by using a Simultaneous thermal analyser (Perkin Elmer, USA), model STA 6000 . The measurements were performed under a nitrogen atmosphere from room temperature to $600^{\circ} \mathrm{C}$ at a heating rate of $5^{\circ} \mathrm{C} / \mathrm{min}$.

\subsection{Adsorption Studies}

Batch adsorption studies were performed at room temperature $\left(25 \pm 1^{\circ} \mathrm{C}\right)$ in polyethylene centrifuge tubes by shaking a variable mass of algae with $50 \mathrm{~mL}$ of phenol solution. Preliminary studies indicate that phenol does not adsorb or interact with the polyethylene tubes. The effect of $\mathrm{pH}$ on the adsorption was investigated at different whole values within the range 2 to 10 for all the samples and placed in a temperature-regulated shaker for at least $12 \mathrm{~h}$. After agitation, samples were filtered and the supernatant was separated. UV-visible spectrometry was used for phenol determination by using the Gales and Booth method [24] with a spectrometer at $\lambda=510 \mathrm{~nm}$, in which antipyrine forms a red/orange complex with phenol.

The $\mathrm{pH}$ effect was used as a screening test to identify the best performing algae. Based on this experiment, algae SG and CM showed the highest adsorption degree. Therefore, these two algae were selected for all other batch experiments. Other effects such as adsorbent dose and initial phenol concentration were then explored to maximize the adsorption capacity. For these experiments, series of tubes containing $50 \mathrm{~mL}$ of phenol solution of different concentrations were mixed with varying amounts of adsorbents. Concentrations ranged from 40 to $300 \mathrm{ppm}$, and masses from 40 to $200 \mathrm{mg}$. The next experiments included the study of the presence of interfering substances on the adsorption of phenol. These substances included salinity $\left(\mathrm{NaCl}, \mathrm{Na}_{2} \mathrm{SO}_{4}\right.$ and $\left.\mathrm{CaCl}_{2}\right)$, detergents (sodium dodecyl sulfonate, SDS $)$ and heavy metal ions $\left(\mathrm{Co}^{+2}, \mathrm{Cu}^{+2}\right.$, and $\left.\mathrm{Pb}^{+2}\right)$ in their nitrate form. For the effect of heavy metals in solution, the $\mathrm{pH}$ of the solution was reduced to $\mathrm{pH} 6$ to assure complete solubility of the heavy metal ions, the adsorption was compared to a control adsorption at the same $\mathrm{pH}$.

\subsection{Data Analysis}

The amount of adsorbed phenol is expressed as Adsorption Percentage (\%ADS) and Adsorption Capacity (q, mg. ${ }^{-1}$ ) calculated as shown in Equations (1) and (2):

$$
\begin{gathered}
\% A D S=\frac{\left(C_{i}-C_{e q}\right) \times 100}{C_{i}} \\
q=\frac{\left(C_{i}-C_{e q}\right) \times V}{m}
\end{gathered}
$$

where $m$ is the mass of the adsorbent expressed in $g, V$ is the volume of the solution in $L$ and $C_{i}$ and $C_{e q}$ are the initial and at the equilibrium concentrations of phenol, expressed in $\mathrm{mg} / \mathrm{L}$, respectively. 
Plots and linear regression were carried out using the statistical software Origin v8.0 (OriginLab, Northampton, MA, USA), obtaining errors between $2.5 \%$ and $4 \%$. Error bars were not added to avoid crowding in the curves. Linear regression reported data includes $\mathrm{R}^{2}$ correlation coefficient values, and p-value defined as the significance relevance of the modeling that is associated with the possibility of an observed result that a null hypothesis is true.

\section{Results and Discussion}

\subsection{Characterization of the Adsorbents}

Good adsorbent candidates should possess optimum chemical, thermal, morphological and textural properties not only to increase the affinity towards a given pollutant, but also to face harsh conditions in which those pollutants exist. FTIR consists in the absorption of infrared radiation by chemical functional groups with a dipole moment. The FTIR of SG and CM revealed the presence of the typical functional groups in algae (Figure 1). According to previously reported data [25], algae are biomass rich in fatty acids, proteins and carbohydrates such as alginate and fucoidans (sulfated polysaccharide). As observed in the FTIR spectra, both algae SG and CM display peaks at 3280, 1680 and 1425 and at $1100 \mathrm{~cm}^{-1}$ attributed to the presence of hydroxyl, carbonyl and hemiacetals, respectively. These functional groups agree with the presence of polyalginate and fucoidan groups in both algae. However, it is important to highlight the higher relative intensity of the peaks of SG, compared to CM. As previously mentioned, SG and CM are brown and green algae, respectively; therefore main structural and chemical composition differences are expected. Brown algae are known to contain a higher concentration of polyalginic acid, which is believed to contribute to the adsorption of pollutants $[14,15]$ This hypothesis is corroborated by a weak peak at $1680 \mathrm{~cm}^{-1}$ and the absence of the peak at $1425 \mathrm{~cm}^{-1}$ for CM. These peaks are associated with the presence of carbonyl groups, main components of alginates. Lastly, the spectra also displays a smaller intensity in CM at $3280 \mathrm{~cm}^{-1}$ (hydroxyl groups), demonstrating a lower amount of polysaccharides, when compared to the SG sample.

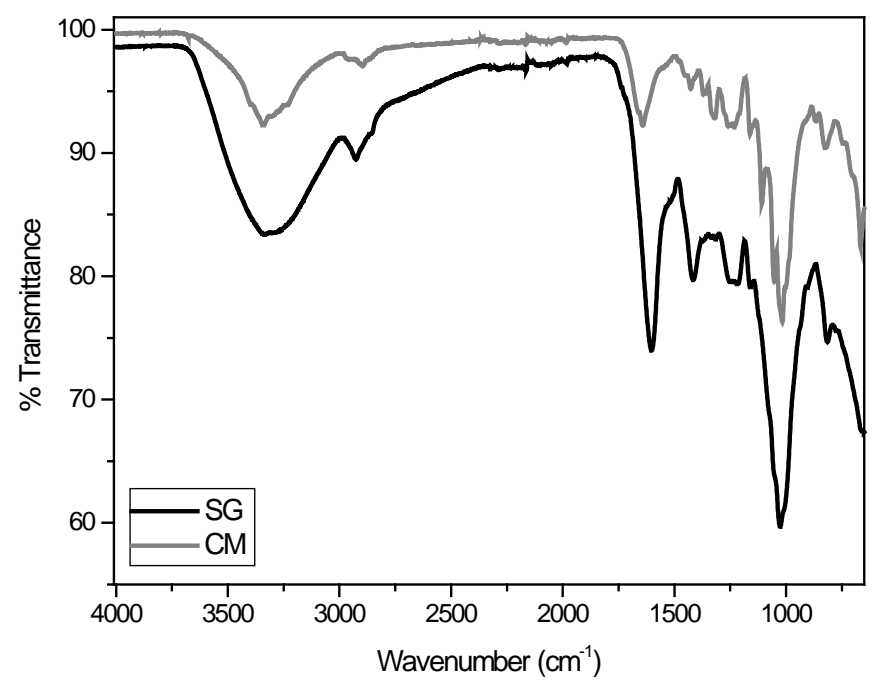

Figure 1. Fourier transformed infrared spectra spectra of Sargassum sp. (SG) and Chaetomorpha (CM) samples before phenol adsorption.

Scanning electron micrographs were used to elucidate the morphological and textural properties of both algae. The micrographs are shown in Figure 2. According to the images, both adsorbents show a highly heterogeneous surface, with valleys, pockets and protrusions, properties of biological materials. These surface features are positive properties for adsorbent candidates. It is always ideal to 
have surface imperfection where the pollutant can be housed and trapped, to facilitate the interaction with the adsorption sites of the biomass. Both adsorbent show similar morphological properties, however a higher surface randomness is observed in SG, demonstrating this adsorbent could have a higher adsorption due to the complexity of its surface. Similar results have been observed with other biomasses such as spent tea leaves [26,27] and other types of marine algae $[15,17]$.

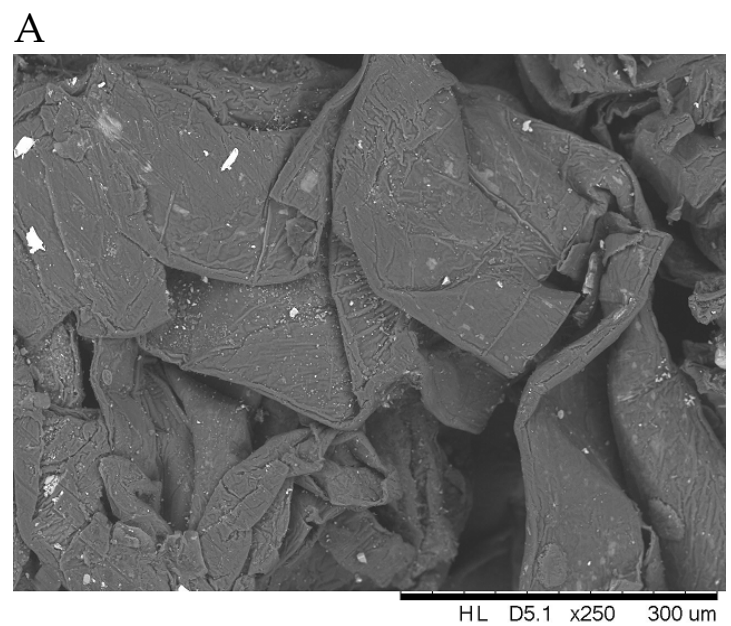

C

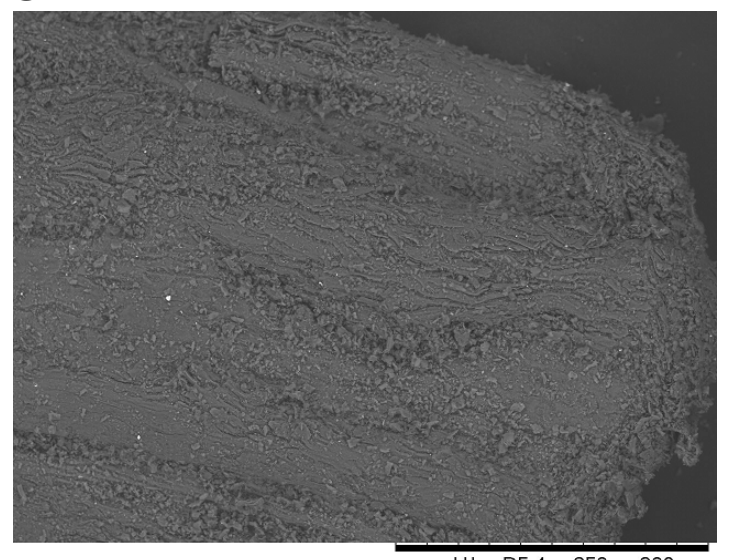

B

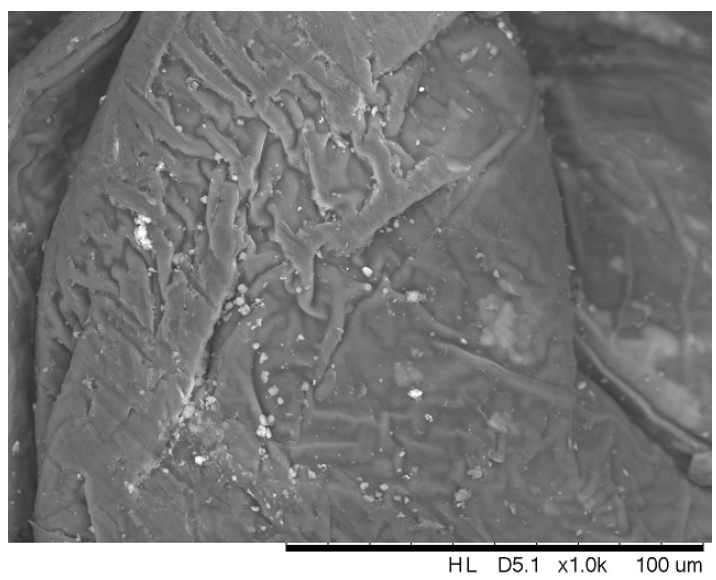

$\mathrm{D}$

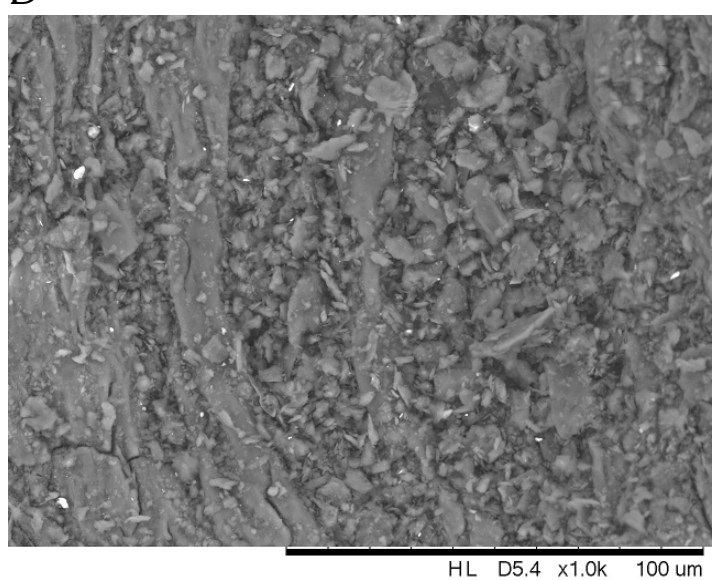

Figure 2. Scanning Electron Micrographs of the adsorbents: Chaetomorpha (A, B), and Sargassum sp. (C, D) at different magnifications.

SEM analysis was coupled with elemental analysis by EDS to determine the presence of key elements that are important in the adsorption of pollutants. The results are shown in Figure 3, indicating the qualitative presence of carbon, oxygen and sulfur. Carbon and oxygen are expected elements due to the biological nature of both adsorbents. However, as observed in the spectra, SG shows the presence of calcium and magnesium ions. Although these species are not structural components of the biomass, their presence suggests a higher content of carboxyl groups in SG. Divalent ions have a special affinity towards carboxyl groups [12-14]. These carboxyl groups were confirmed by FTIR (Figure 1) and now elucidated by the presence of $\mathrm{Ca}^{+2}$ and $\mathrm{Mg}^{+2}$ on the raw SG adsorbent. Algae CA does not show substantial amounts of these ions, supporting the idea of the lower number of carboxyl functional groups. These groups are able to form strong dipole and hydrogen bonding with the charged and uncharged phenol pollutant and lead us to the adsorption mechanism on algal biomass.

Finally, the thermal properties of the adsorbents were studied by thermogravimetric analysis (TGA). Even though these adsorbent are not expected to be used at high temperature, the results can be translated into thermal, physical and mechanical resistance that these adsorbent possess. 
A

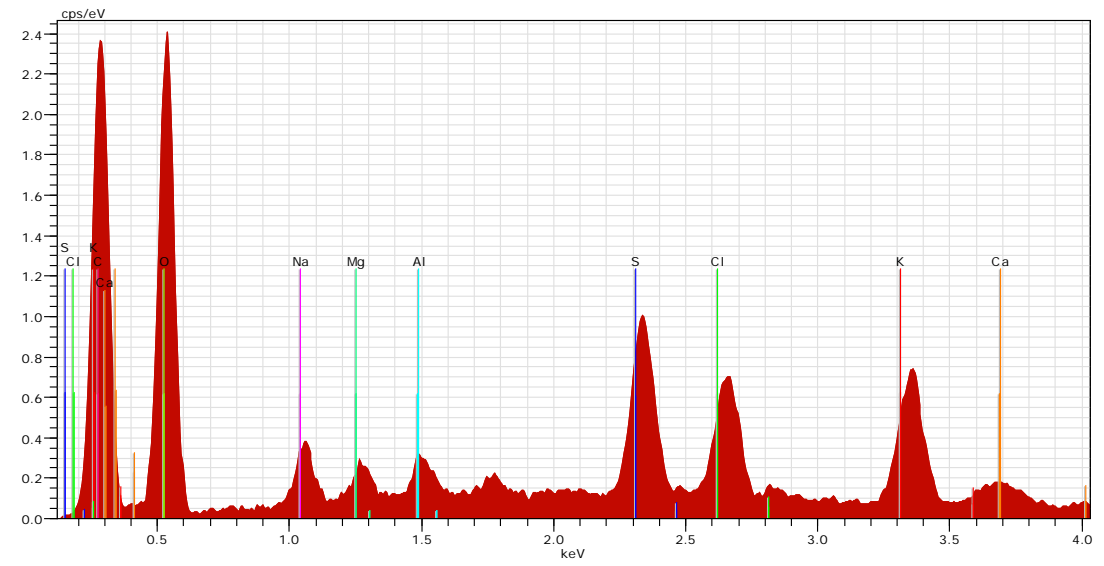

\begin{tabular}{|c|c|}
\hline ELEMENT & ATOM \% \\
\hline CARBON & 52.75 \\
\hline OXYGEN & 41.40 \\
\hline SULFUR & 1.49 \\
\hline POTASSIUM & 1.46 \\
\hline CHLORINE & 1.12 \\
\hline SODIUM & 0.89 \\
\hline
\end{tabular}

B

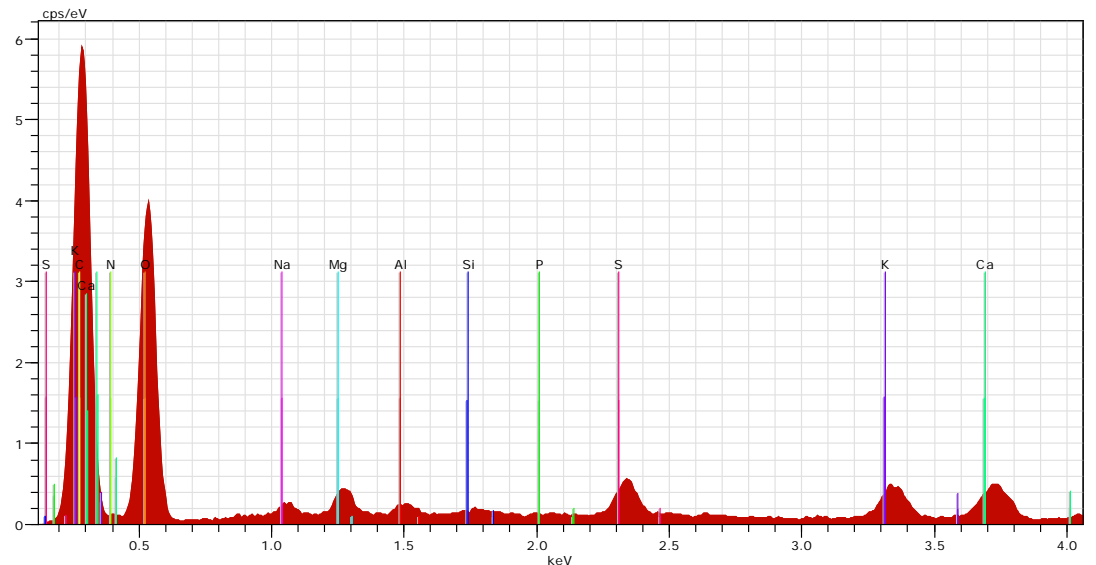

\begin{tabular}{|c|c|}
\hline ELEMENT & ATOM \% \\
\hline CARBON & 55.09 \\
\hline OXYGEN & 42.35 \\
\hline CALCIUM & 0.77 \\
\hline POTASSIUM & 0.57 \\
\hline SULFUR & 0.47 \\
\hline MAGNESIUM & 0.38 \\
\hline
\end{tabular}

Figure 3. Energy Dispersive X-ray spectra and Atom Percent Abundance of the most prevalent elements for both adsorbents Chaetomorpha (A) and Sargassum sp. (B). Other elements that are labeled on the spectra, have \%ATOM smaller than $0.89 \%$ and $0.38 \%$ for Chaetomorpha and Sargassum sp., respectively.

It is expected that materials that resist thermal decomposition at higher temperature, are expected to resist more adverse conditions such as oxidation, light degradation and other adverse environmental conditions that might be present in real wastewaters. Both TGA analyses under nitrogen atmosphere (non-oxidizing conditions) are shown in Figure 4. According to the curves, both samples show an initial mass loss above $100{ }^{\circ} \mathrm{C}$ corresponding to loss of moisture. Then, there is a slow thermal decomposition for both samples until $230^{\circ} \mathrm{C}$. This mass drop could be attributed to one type of components, most likely volatile or weakly bonded molecules. It is important to highlight that SG has a higher mass loss than CA within this temperature range $\left(100-230^{\circ} \mathrm{C}\right)$. Then, a drastic mass loss is observed between $230{ }^{\circ} \mathrm{C}$ and $375{ }^{\circ} \mathrm{C}$. Within this temperature range, the decomposition of CA reflects the loss of at least 4 types of compounds (demonstrated by the number of inflections points), whereas SG only shows 2 . This results agrees with the chemical composition of green algae (CA), which are rich in proteins, lipids and carbohydrates, as described elsewhere [7,18]. On the other hand, brown algae, such as SG, are richer in carbohydrates such as polyalginate and fucoidans. Lastly, a final and slow mass loss is observed above $375{ }^{\circ} \mathrm{C}$, representing stronger biopolymers and fiber. In conclusion, both adsorbents display optimum thermal resistance and are highly stable at temperatures up to $230{ }^{\circ} \mathrm{C}$ (maximum mass loss of $10 \%$ ). However, CA algae shows a better thermal resistance when compared to SG. This could be explained by the more heterogeneous composition of green algae, including nucleic acids, lipids, proteins and carbohydrates. 


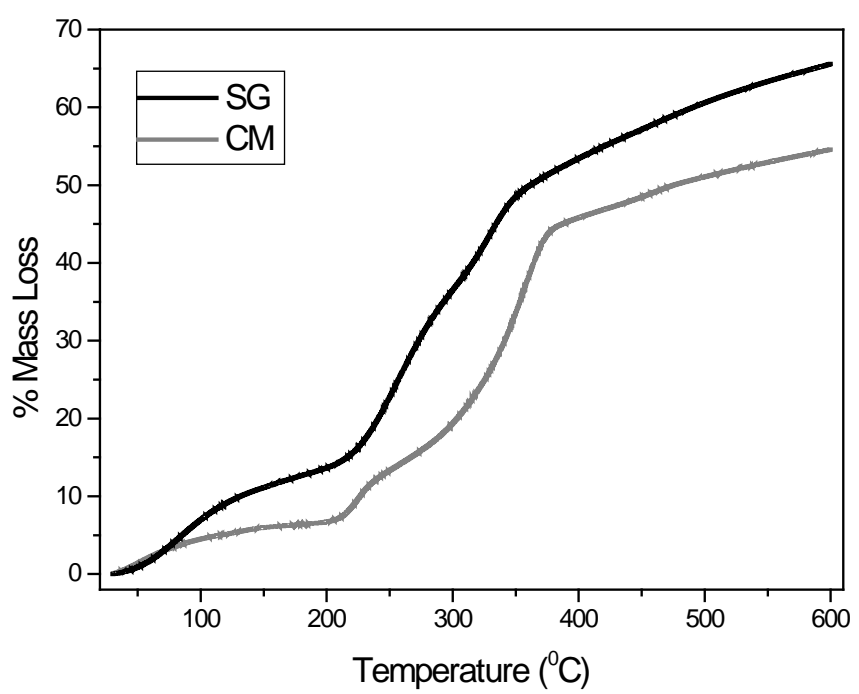

Figure 4. Thermogravimetric analysis of both adsorbents under nitrogen atmosphere at a heating rate of $5{ }^{\circ} \mathrm{C} / \mathrm{min}$.

\subsection{Adsorption Tests}

\subsubsection{Effect of Initial $\mathrm{pH}$ Value}

$\mathrm{pH}$ is one of the most important factors in the adsorption of environmental contaminants in aqueous solutions since it influences the solution chemistry of phenols (i.e., hydrolysis, redox reactions, polymerization and complexation). $\mathrm{pH}$ also has a strong influence on the speciation and the sorption availability of phenolic compounds as well as the ionic state of functional groups on the surface of adsorbents $[7,8,28]$.

Figure 5 shows the effect of solution $\mathrm{pH}$ on the adsorption of phenol at room temperature. For all algae samples, the highest adsorption capacity is reported at $\mathrm{pH} 10$. These phenomena can be explained as the product of electrostatic repulsion/attraction between the adsorbent and the adsorbate. Recent studies [29] demonstrated that marine algae have apparent ionization constants around 3.0 whereas at higher $\mathrm{pH}$ values, the algal surfaces are negatively charged. At the same time, phenol $\left(\mathrm{pK}_{\mathrm{a}}=9.9\right)$ becomes negatively charged with increasing $\mathrm{pH}$. Consequently, the higher concentration of hydroxonium ions in the solution, promote the prevalence of neutral phenol, and the deprotonation of the algal surface at higher $\mathrm{pH}$ values, favor adsorption. Surprisingly, the adsorption is greatly decreased at low $\mathrm{pH}$ values, indicating that an efficient adsorption interaction only occurs between the adsorbent and the negatively charged phenol. Moreover, no substantial changes were observed at the apparent $\mathrm{pK}_{\mathrm{a}}$ value of alginate, indicating that the adsorption mechanism is mainly driven by the chemistry of phenol and not by the ionization of the adsorbent. Higher $\mathrm{pH}$ values were not studied due to the impractical use of solutions at extremely basic ranges.

Based on these results and the FTIR data, we propose a polar adsorption of phenol onto SG and CM. The adsorption interactions should occur between the hydroxyl groups of the algae and the phenoxide ion, through the formation of hydrogen bonds. Alginate should not intervene in the removal of phenol due to electrostatic repulsion of alginate anions and phenoxide at the highest adsorption $\mathrm{pH}$. Marine algae are mainly composed of a polysaccharide named polyalginic acid, which contains mixtures of mannuronic $(\mathrm{M})$ and guluronic $(\mathrm{G})$ acid (carboxylated monosaccharides) [25,29]. These polysaccharides are rich in hydroxyl groups and observed in higher percentages in brown algae (SG and OD). Although alginates have reported a high adsorptive removal of other pollutants [12-18], their adsorption efficiency relies on the appropriate $\mathrm{M}$ and $\mathrm{G}$ sequence in the polysaccharide. According to the results, OD, also a brown algae, shows a low adsorption, which could be tentatively explained by the unfavorable proportion and sequencing of $\mathrm{M}$ and $\mathrm{G}$ units in its structure. This important role 
has also been explained and observed by Rubin et al. [30]. More studies on monosaccharides content and sequencing are needed to support this hypothesis.

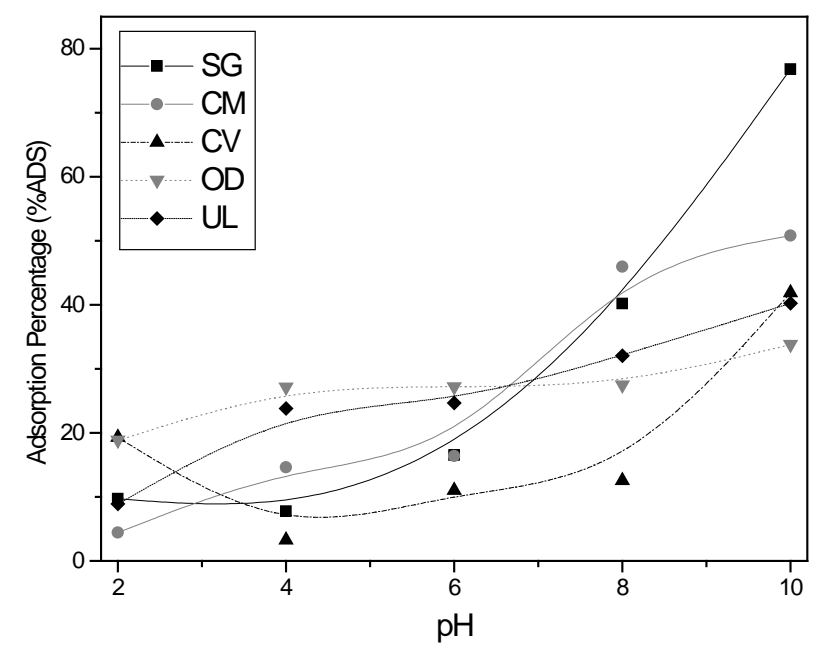

Figure 5. $\mathrm{pH}$ effect on the adsorption of phenol on marine algae. Mass of adsorbent: $50 \mathrm{mg}$ and Phenol concentration: $50 \mathrm{mg} / \mathrm{L}$.

\subsubsection{Effect of Adsorbent Dose}

A sustainable and efficient bioremediation technique should not only be "green" but also minimize the amount of biomass to be used in the process. Figure 6 displays the role of the adsorbent dose on the adsorption of phenol at the optimum $\mathrm{pH}$. According to the results, higher masses of $\mathrm{CM}$ increase the adsorption, reaching a steady value around $100 \mathrm{mg}$. This indicates that masses higher than $100 \mathrm{mg}$ have no substantial impact on the adsorption. Conversely, SG shows a decreased adsorption with increasing masses. This can be explained by the formation of aggregates with SG. In solution, SG tends to form clumps (clearly observed in the adsorption tube), decreasing its surface area that is exposed to the solution. This phenomenon was not experimentally observed in CM, where a homogeneous particle distribution was observed throughout the solution. Therefore, optimum masses of $40 \mathrm{mg}$ and $100 \mathrm{mg}$ were taken for SG and CM, respectively. Similar adsorption aggregation behavior was reported by Rubin et al. [16,30] for a different type of brown algae.

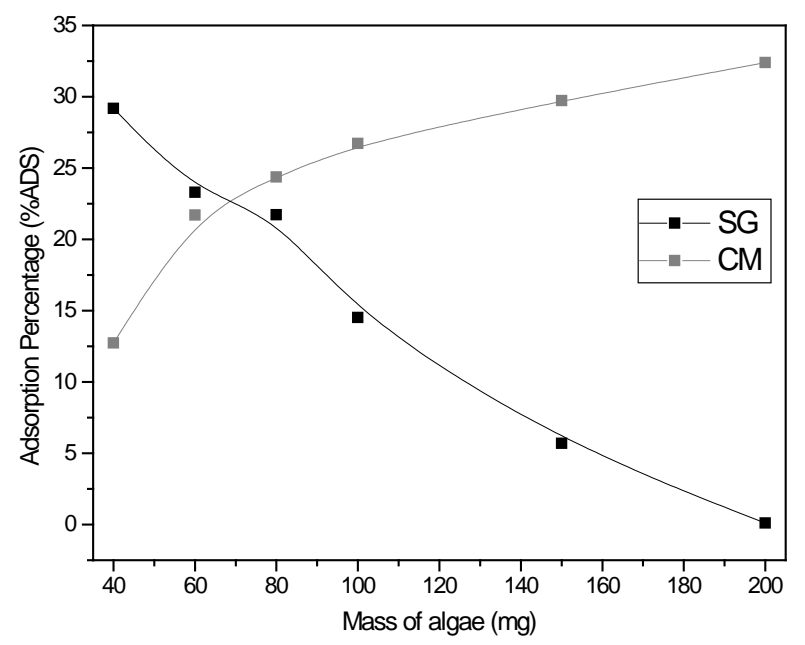

Figure 6. Effect of the adsorbent dose on the adsorption of phenol on marine algae. Initial solution pH: 10 and Phenol concentration: $100 \mathrm{mg} / \mathrm{L}$. 


\subsubsection{Equilibrium Modelling}

Adsorption isotherms have been widely used to describe the distribution of a substance (adsorbate) from one phase onto a solid surface (adsorbent). This adsorbate transport is driven by thermodynamic and equilibrium factors that are expressed in terms of mathematical equations and based on different assumptions $[7,18]$. The Langmuir theory assumes that (i) the adsorbent's surface has a defined number of active sites that are energetically uniform; (ii) adsorbed species do not interact on the adsorbent's surface, meaning that the adsorption of an adsorbate does not promote nor inhibit the adsorption a second adsorbate species; and (iii) the adsorption saturation is reached when a monolayer of adsorbate has been formed on the surface of the adsorbent. On the other hand, as opposed to Langmuir's theory, Freundlich equation assumes a logarithmic decrease in the adsorption enthalpy with an increasing number of occupied adsorption sites of a rather energetically heterogeneous adsorbent surface. Both adsorption isotherm equations can be written in their linearized forms and the Langmuir and Freundlich constants can be calculated, according to Equations (3) and (4), respectively.

$$
\begin{gathered}
\frac{1}{q}=\frac{1}{q_{\max }}+\frac{1}{b \times q_{\max } \times C_{e q}} \\
\ln q=\ln k_{F}+\frac{1}{n} \times \ln C_{e q}
\end{gathered}
$$

where $q_{\max }\left(\mathrm{mg} \cdot \mathrm{g}^{-1}\right)$ and $\mathrm{b}(\mathrm{L} / \mathrm{mg})$ are the Langmuir constants related to the maximum adsorption capacity and to the adsorption energy, respectively. The parameters $k_{F}$ and $1 / n$ are the Freundlich constants related to the adsorption capacity and the adsorption intensity, respectively. In addition to these models, Tempkin, proposed a different theory based on the assumption that the heat of adsorption would decrease linearly with the increase of coverage of adsorbent. The mathematical equations of Tempkin's theory is expressed with Equation (5):

$$
q=\frac{R \times T}{b_{T}} \ln \left(a_{T} \times C_{e q}\right)
$$

in which $R$ is the gas constant, $T$ is the absolute temperature in Kelvin, $b_{T}$ is a constant related to the heat of adsorption and $a_{T}$ is the Tempkin isotherm constant. The Tempkin isotherm equation has been widely applied to describe the adsorption on heterogeneous surfaces.

The isotherms obtained at room temperature for the adsorption of phenol at the optimum adsorption $\mathrm{pH}$ and adsorbent doses are given in Figure 7, whereas Table 1 presents the corresponding constants along with the coefficients of linear correlation $\left(R^{2}\right)$ associated with each linearized model.

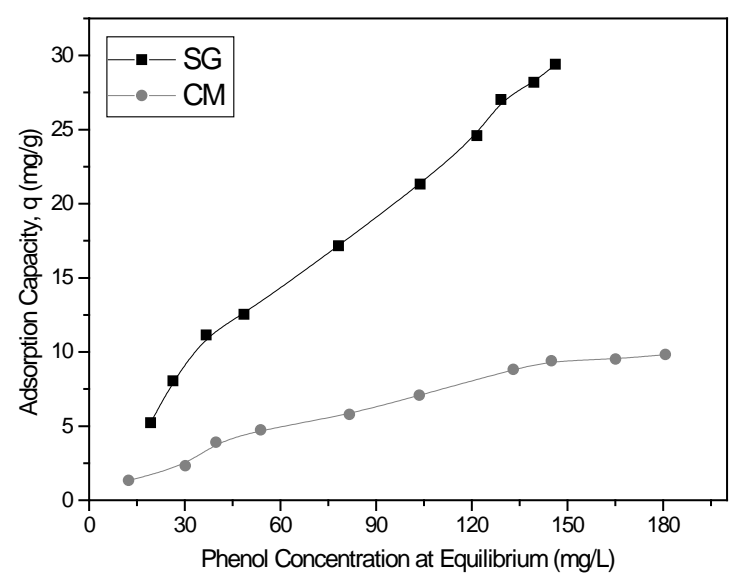

Figure 7. Concentration effect and isotherm curves for the adsorption of phenol on marine algae. Initial solution pH: 10 and masses of SG and CM are $40 \mathrm{mg}$ and $100 \mathrm{mg}$, respectively. 
Table 1. Calculated Constants and Parameters of the isotherm models for the adsorption of phenol onto Sargassum sp. (SG) and Chaetomorpha (CM) algae.

\begin{tabular}{ccc}
\hline Isotherm Model & SG & CM \\
\hline Langmuir & & \\
\hline$q_{\text {max }}\left(\mathrm{mg} \cdot \mathrm{g}^{-1}\right)$ & 82.10 & 17.69 \\
$b(\mathrm{~L} / \mathrm{mg})$ & 0.0038 & 0.0064 \\
$\mathrm{R}^{2}$ & 0.98 & 0.98 \\
$\mathrm{SD}^{2}$ & $5.1 \times 10^{-5}$ & $9.64 \times 10^{-4}$ \\
$p$ & $<0.0001$ & $<0.0001$ \\
\hline Freundlich & & \\
\hline$k_{F}$ & 0.579 & 0.199 \\
$1 / n$ & 0.787 & 0.767 \\
$R^{2}$ & 0.99 & 0.98 \\
$S D^{2}$ & $5.1 \times 10^{-3}$ & $9.22 \times 10^{-3}$ \\
$p$ & $<0.0001$ & $<0.0001$ \\
\hline Tempkin & & \\
\hline$a_{T}$ & 0.0711 & 0.083 \\
$b_{T}$ & 209.42 & 696.201 \\
$R^{2}$ & 0.962 & 0.95 \\
$S D^{2}$ & 3.36 & 0.575 \\
$p$ & $<0.0001$ & $<0.0001$ \\
\hline
\end{tabular}

As observed in Table 1, the maximum value for the adsorption capacity for phenol was obtained by the marine seaweed SG $\left(q_{\max }=82.10 \mathrm{mg} \cdot \mathrm{g}^{-1}\right)$, followed by CM $\left(q_{\max }=17.7 \mathrm{mg} \cdot \mathrm{g}^{-1}\right)$. As for the coefficients of correlation, we can postulate that the three models are adequate for modelling the isotherm of the removal of phenol by both adsorbents. Therefore, a mixed adsorptive mechanism under these experimental conditions can be suggested. The modelling of the adsorption process also indicates that although SG has a higher adsorption capacity than CM, CM reports a higher adsorbate/adsorbent affinity, as indicated by the $b$ Langmuir constant [26,27]. This higher affinity of $\mathrm{CM}$ is corroborated by the higher $\mathrm{b}_{\mathrm{T}}$ Tempkin constant for $\mathrm{CM}$, which is associated with the heat of adsorption. Lastly, the Freundlich theory shows a spontaneous adsorption as denoted by the $1 / n$ value, with values around 0 and 1 for both adsorbents. The isotherm results demonstrate that these marine algae are competitive adsorbent when compared to other previously studied seaweed $[15,16]$.

\subsubsection{Effect of Salinity}

The adsorption capacity is strongly associated with different types of electrostatic interactions (complexation, ionic exchange, and electrostatic forces) between the adsorbate and the adsorbent. These coulombic interactions strongly depend on the electrostatic environment which determines the existence of the interaction. Other ions in solution compete for the active sites $[5,6]$. Figure 8 displays the effect of different salts on the adsorption of phenol. Competition between the phenol and the salt for the active sites was expected. However, as shown in Figure 8, SG increases its phenol affinity at increasing salt concentrations. This could be explained by the non-electrostatic adsorption mechanism of phenol. The presence of salt makes the solution more polar and therefore phenol (with its aromatic ring) tends escape from this unfriendly polar environment and promote the adsorption onto the surface and pores of the algae. On the other hand, $\mathrm{CM}$ shows a completely different profile. The adsorption improves at low salt concentration, and dramatically decreases at relatively higher salt concentrations. These results could be attributed to the different types of actives sites on SG and CM. Apparently, in SG, the adsorption sites for phenol are not shared by the adsorption sites for the salt ions, and therefore SG is able to tolerate salts. 


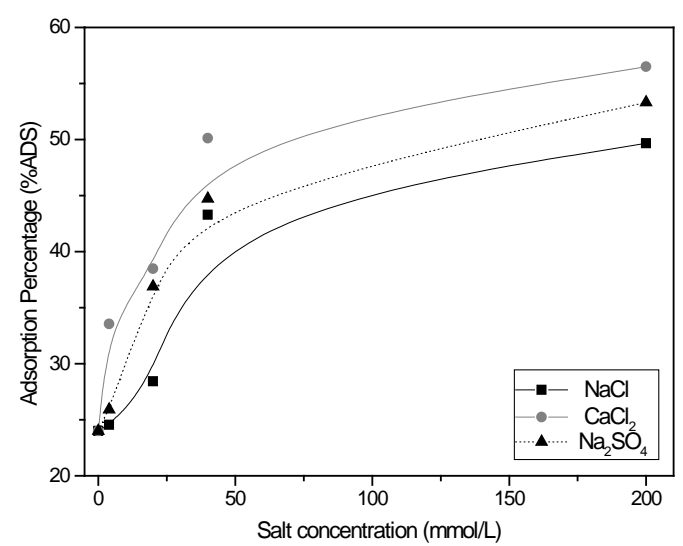

(a)

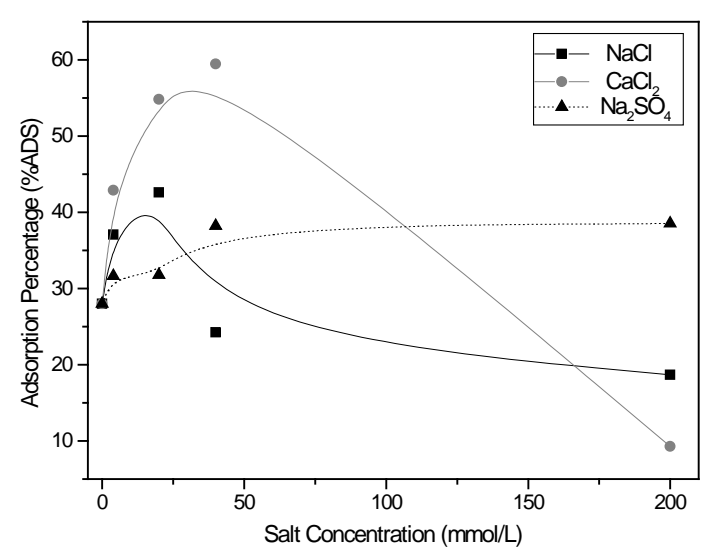

(b)

Figure 8. Salinity effect on the adsorption of phenol onto Sargassum sp. (a) and Chaetomorpha (b). Phenol concentration $100 \mathrm{mg} / \mathrm{L}$; Initial solution pH: 10; masses of Sargassum sp. and Chaetomorpha: $40 \mathrm{mg}$ and $100 \mathrm{mg}$, respectively.

Conversely, the adsorption sites of CM are shared by phenol and salt ions. Although the adsorption is initially increased at low salt concentrations, the adsorption decreases, especially with $\mathrm{NaCl}$ and $\mathrm{CaCl}_{2}$. This demonstrates an interfering effect of chloride ions on the adsorption of phenol onto CM. This negative effect is not observed in $\mathrm{Na}_{2} \mathrm{SO}_{4}$, where a slight adsorption increase is actually observed. The small increase of adsorption at low salt concentration could be explained due to the partition coefficient of phenol between the polar bulk solution and the solvent-isolated active sites of $\mathrm{CM}$. However, when the salt concentration increases, the competition between chloride and phenol ions decreases and the adsorption of phenol decreases. This effect is not observed with sulfate ions, because they are known to be very poor nucleophiles and therefore do not compete for active sites (Lewis bases).

\subsubsection{Effect of the Presence of Detergent}

The real challenge of wastewaters resides in the complexity of the solution, which is expected to contain a broad diversity of inorganic and organic species that may prevent the binding of the target pollutants to the active adsorption sites (steric hindrance). To explore the role steric factors on the adsorption, phenol solutions were mixed with an anionic detergent, namely sodium dodecyl sulfonate (SDS), which is an inert molecule and highly soluble in water. Preliminary tests with visible spectrophotometry with and without SDS showed no difference in the absorbance for phenol quantification, demonstrating that SDS does not interact with phenol or the adsorbents. It is expected that SDS will sterically interfere with the appropriate interaction between the adsorbent and the phenol at the solution level. Results are shown in Figure 9, demonstrating that SDS promotes the adsorption of phenol for both adsorbents with similar intensities. This effect could be attributed to a change in the phenol availability in the solution, and not to the type of adsorbent. Although SDS is an amphipathic molecule, it is not able to trap phenol in a micelle. At pH 10, most of the phenol is ionized at the level of the phenoxide ion, but is also hydrophobic due to the presence of the aromatic ring. Our explanation for this adsorption increase could be understood as the stabilization of the aromatic ring of phenoxide in solution by the SDS hydrophobic side chains. This could potentially make phenoxide ions more accessible and chemically available in the solution to be adsorbed by the algae. Consequently, SDS promotes a more amphipathic environment and enhances the transport of phenol from the bulk solution into the algal surface. 


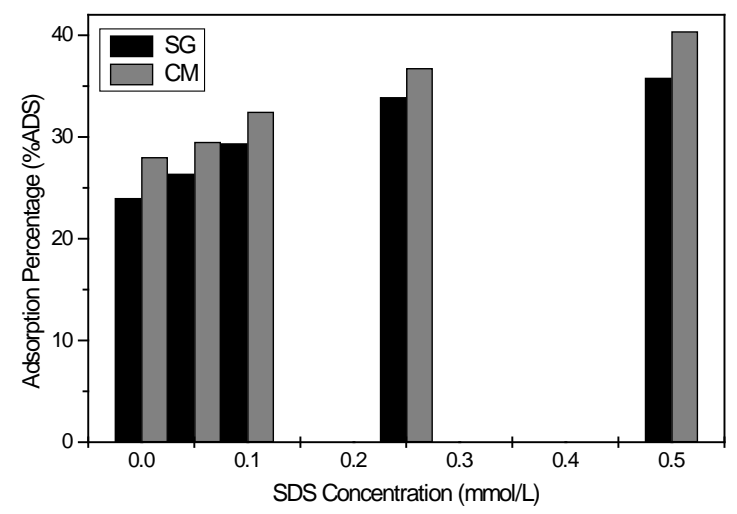

Figure 9. Effect of the presence of detergent Sodium dodecyl sulphonate (SDS) on the adsorption of phenol onto Sargassum sp. (SG) and Chaetomorpha (CM). Phenol concentration $100 \mathrm{mg} / \mathrm{L}$; Initial solution pH: 10; masses of SG and CM: $40 \mathrm{mg}$ and $100 \mathrm{mg}$, respectively.

\subsubsection{Effect of the Presence of Heavy Metal Ions}

Industrial contamination comprises inorganic and organic pollutants and heavy metals are a large component of this pollution. Heavy metal ions are introduced into industrial wastewaters by several processes and become a strong competitor for phenol. Algae have demonstrated a high affinity towards heavy metals as well [12-14], and therefore it is crucial to evaluate the effect of these species on the adsorption of phenol. The solution $\mathrm{pH}$ for this test had to be adjusted to $\mathrm{pH} 6$ to maintain the heavy metal ions in solution. As displayed in Figure 10, divalent copper, lead and cobalt ions have a positive effect on the adsorption of phenol at low concentrations (5-100 ppm) for both algae. However, as the metal concentration increases, the adsorption decreases. This could be explained by the coverage of the surface of the adsorption at higher metal concentrations, which prevents the binding of phenol, even on different actives sites. At low metal concentration, it can be postulated that adsorbed heavy metal ions serve as bridges between the adsorbent and phenol (due to their positive charge and Lewis acidity). Nevertheless, with an increasing heavy metal ions concentration, an increasing concentration of the counter ions such as nitrate is also observed, competing for the active sites. In conclusion, heavy metal ions have a negative effect on the adsorption of phenol for both algae, with a more intense effect with $\mathrm{Pb}$, due to a stronger algae/lead (II) ions affinity. Cobalt (II) ions are not known to be strongly adsorbed onto algae [13] and therefore do not represent an interfering species with respect to the adsorption of phenol.

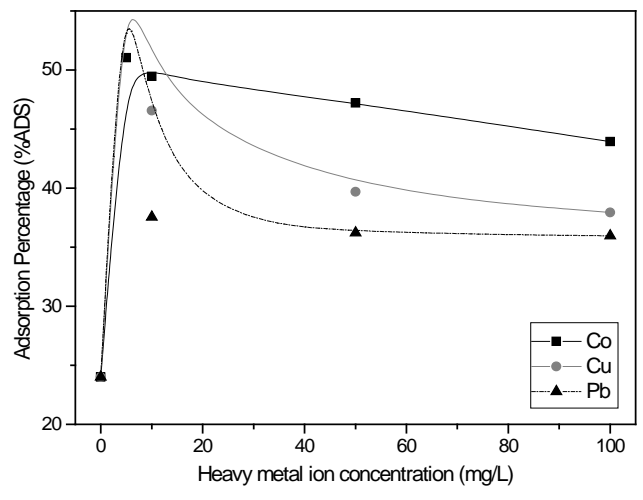

(a)

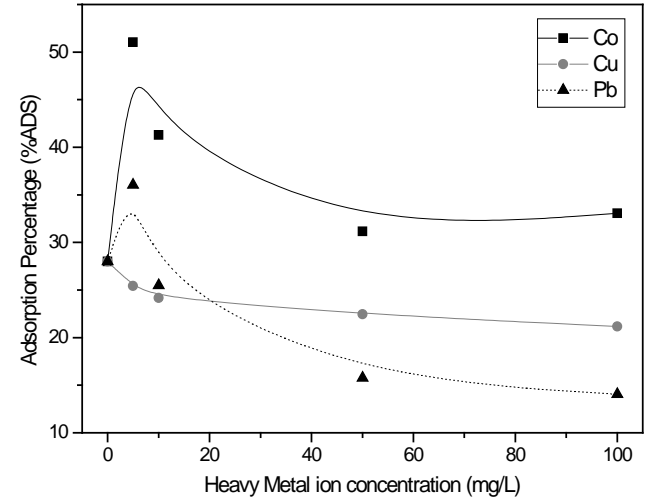

(b)

Figure 10. Effect of the presence of heavy metal ions on the adsorption of phenol onto Sargassum sp. (a) and Chaetomorpha (b). Phenol concentration $100 \mathrm{mg} / \mathrm{L}$; Initial solution pH: 6; masses of Sargassum sp. and Chaetomorpha: $40 \mathrm{mg}$ and $100 \mathrm{mg}$, respectively. 


\section{Conclusions}

The development of new alternatives for the decontamination of industrial runoffs with high level of phenol and its derivatives is still a scientific concern. Alternative and eco-friendly adsorbents that do not produce byproducts are also priority materials that need to be studied. This study proposes native marine algae from Puerto Rico as candidates for the adsorption of phenol from solutions. Results indicate that $\mathrm{pH}$, salinity and the presence of interfering substances have an important impact on the adsorption. Experimental data indicates that phenol prefers to adsorb onto Sargassum (SG). It is hypothesized that hydroxyl groups from the structural polysaccharides are responsible for this preference due to the formation of hydrogen bonds and dipole interactions. Langmuir, Tempkin and Freundlich isotherm models were fitted to the results, suggesting a combined adsorption mechanism, with maximum adsorption capacities of 82.1 , and $17.7 \mathrm{mg} \cdot \mathrm{g}^{-1}$ for SG and CM, respectively. Equilibrium experimental data indicate that $\mathrm{pH}$ has a strong effect on the adsorption and allow high adsorption at $\mathrm{pH} 10$ and using a minimum mass of $40 \mathrm{mg}$ and $100 \mathrm{mg}$ for SG and $\mathrm{CM}$, respectively. Finally, the adsorbent and the mechanism were characterized by instrumental analysis. FTIR studies demonstrated that carboxyl, hydroxyl and carbonyl groups could be associated with the adsorption mechanism of phenol. SEM/EDS experiments suggest that these algae have morphological and chemical properties that are appropriate for good adsorbents. SEM showed pockets and protrusions that are essential to house and seclude pollutants. EDS indicates the presence of key elements that could be associated with specific functional groups that are associated with adsorption of phenol. Finally, TGA demonstrated that both adsorbents can tolerate temperatures as high as $230{ }^{\circ} \mathrm{C}$, indicating that these materials have mechanical and thermal properties that make them good candidates as adsorbers of phenol under more adverse conditions. The use of renewable and naturally occurring materials as adsorbents of pollutants is a new area in bioremediation that needs to be further explored. Marine algae have demonstrated that they can be used to produce biofuels as well as to decontaminate inorganic and organic pollutants from contaminates wastewaters.

Acknowledgments: This work was supported by the CRSP and CSTEP programs and the Science Department at BMCC/CUNY. This work was supported by the C3IRG grant \#1224 (to A.E.N.) the National Science Foundation grant \# EEC-1263250 to Rutgers University, and a grant from the US Department of Education and the Center for Renewable Energy and Sustainability to the UPR Río Piedras.

Author Contributions: Abel E. Navarro and Anibal Hernandez-Vega prepared the adsorbents and conducted the adsorption experiments; Loretta Roberson contributed to the algae characterization and data analysis; Md. Emran Masud performed the material characterization experiments; Abel E. Navarro and Liz Diaz-Vasquez designed the research and equally contributed to the writing and editing of the manuscript. All authors read and approved the final manuscript.

Conflicts of Interest: The authors declare no conflict of interest.

\section{References}

1. US Environmental Protection Agency. Toxic Release Inventory and Community Right to Know; US EPA: Washington, DC, USA, 2002.

2. US Environmental Protection Agency. Hazard Information on Toxic Chemicals Added to EPCRA Section 313 under Chemical Expansion; US EPA: Washington, DC, USA, 2002.

3. Halden, R. Contaminants of Emerging Concern in the Environment: Ecological and Human Health Considerations; American Chemical Society: Washington, DC, USA, 2010.

4. Navarro, A.; Chang, E.; Chang, P.; Yoon, S.; Manrique, A. Separation of dyes from aqueous solutions by magnetic alginate beads. Trends Chromatogr. 2013, 8, 31-41.

5. Srinivasan, A.; Viraraghavan, T. Decolorization of dye wastewaters by biosorbents: A review. J. Environ. Manag. 2010, 9, 1915-1929. [CrossRef] [PubMed]

6. Tripathi, P.; Srivastava, V.; Kumar, A. Optimization of an azo dye batch adsorption parameters using Box-Behnken design. Desalination 2009, 249, 1273-1279. [CrossRef]

7. Liu, Y.; Wang, J. Fundamentals and Applications of Biosorption Isotherms, Kinetics and Thermodynamics; Nova Science Publishers: New York, NY, USA, 2009. 
8. Lazo, J.; Navarro, A.E.; Sun-Kou, R.; Llanos, B. Synthesis and Characterization of organophilic clays and their application as phenol adsorbents. Rev. Soc. Quím. Perú 2008, 74, 3-19.

9. Navarro, A.E.; Cuizano, N.; Lazo, J.; Sun-Kou, R.; Llanos, B. Comparative study of the removal of phenolic compounds on biological and non-biological adsorbents. J. Hazard. Mater. 2008, 164, 1439-1446. [CrossRef] [PubMed]

10. Navarro, A.E.; Cuizano, N.; Lazo, J.; Sun-Kou, R.; Llanos, B. Insights into Removal of phenol from aqueous solutions by low cost adsorbents: Clays versus algae. Sep. Sci. Technol. 2009, 44, 2491-2509. [CrossRef]

11. Deng, H.; Liu, J.; Li, G.; Zhang, G.; Wang, X. Adsorption of methylene blue on adsorbent materials produced from cotton stalk. Chem. Eng. J. 2011, 172, 326-334. [CrossRef]

12. Cuizano, N.; Reyes, U.; Dominguez, S.; Llanos, B.; Navarro, A.E. Relevance of the $\mathrm{pH}$ on the adsorption of metallic ions by brown seaweeds. Rev. Soc. Quím. Perú 2010, 76, 123-130.

13. Reyes, U.; Navarro, A.E.; Llanos, B. Use of seaweeds for Biosorption of Cupric ions in aqueous solutions. Rev. Soc. Quím. Perú 2009, 75, 353-361.

14. Cuizano, N.; Llanos, B.; Navarro, A.E. Application of marine seaweeds as lead (II) biosorbents: Analysis of the equilibrium state. Rev. Soc. Quím. Perú 2009, 75, 33-43.

15. Navarro, A.E.; Cuizano, N.; Portales, R.; Llanos, B. Adsorptive Removal of 2-nitrophenol and 2-chlorophenol by cross-linked algae from aqueous solutions. Sep. Sci. Technol. 2008, 43, 3183-3199. [CrossRef]

16. Rubin, E.; Rodriguez, P.; Herrero, R.; Sastre de Vicente, M. Biosorption of phenolic compounds by the brown alga Sargassum. muticum. J. Chem. Technol. Biotechnol. 2006, 81, 1093-1099. [CrossRef]

17. Kotrba, P.; Mackova, M.; Macek, T. Microbial Biosorption of Metals; Springer: New York, NY, USA, 2011.

18. Volesky, B. Sorption and Biosorption; BV SORBEX Inc.: Montreal, QC, Canada, 2004.

19. Serrano, K.; Musaev, H.; Irkakhujaev, S.; Navarro, A.E. Use of lignocellulosic wastes as adsorbents of divalent cobalt (II) ions from contaminated solutions. Trends Chromatog. 2014, 9, 65-72.

20. Zarzar, A.; Hong, M.; Llanos, B.; Navarro, A.E. Insights into the eco-friendly adsorption of caffeine from contaminated solutions by using hydrogel beads. J. Environ. Anal. Chem. 2015, 2, 4.

21. Bellatin, L.; Herrera, O.; Navarro, A.E.; Sun, R.; Llanos, B. Study on the biosorption of basic yellow 57 dye, basic blue 99 and acid red 18 from hair dyes onto green tea leaves. Rev. Soc. Quim. Perú 2014, 80, 9-23.

22. Rawajfih, Z.; Nsour, N. Characteristics of phenol and chlorinated phenols sorption onto surfactant-modified bentonite. J. Colloid Interface Sci. 2006, 298, 39-49. [CrossRef] [PubMed]

23. Braccini, I.; Pérez, S. Molecular basis of $\mathrm{Ca}^{2+}$-induced gelation in alginates and pectins: The Egg-Box model revisited. Biomacromolecules 2001, 2, 1089. [CrossRef] [PubMed]

24. Gales, M.; Booth, R. Automated 4AAP phenolic method. J. AWWA 1976, 68, 540.

25. Cuizano, N.; Llanos, B.; Navarro, A.E. Elimination of 2-chlorophenol from aqueous solutions by marine algae: Evidences of adsorption mechanism. Rev. Soc. Quím. Perú 2009, 75, 213-220.

26. Japhe, T.; Zhdanova, K.; Rodenburg, L.; Roberson, L.; Navarro, A.E. Factors affecting the Biosorption of 2-Chlorophenol using spent tea leaf wastes as adsorbents. J. J. Environ. Sci. 2015, 1, 010.

27. Choi, Y.; Isaac, P.; Irkakhujaev, S.; Masud, M.E.; Navarro, A.E. Use of spent tea wastes-chitosan capsules for the removal of divalent copper ions. J. J. Environ. Sci. 2015, 1, 003.

28. Sponza, A.; Fernandez, N.; Yang, D.; Ortiz, K.; Navarro, A.E. Comparative Sorption of methylene blue onto hydrophobic clays. Environments 2015, 2, 388-398. [CrossRef]

29. Navarro, A.E.; Portales, R.; Sun-Kou, R.; Llanos, B. Effect of pH on phenol biosorption by seaweeds. J. Hazard. Mater. 2008, 156, 405-411. [CrossRef] [PubMed]

30. Rubin, E.; Rodriguez, P.; Herrero, R.; Cremades, J.; Barbara, J.; Sastre de Vicente, M. Removal of methylene blue from aqueous solutions using as biosorbent Sargassum muticum: An invasive microalga in Europe. J. Chem. Technol. Biotechnol. 2005, 80, 291-298. [CrossRef]

(C) 2016 by the authors; licensee MDPI, Basel, Switzerland. This article is an open access article distributed under the terms and conditions of the Creative Commons Attribution (CC-BY) license (http://creativecommons.org/licenses/by/4.0/). 